\title{
Experiencias fronterizas y efectos de las movilidades sociales y de clase
}

\section{Barbara Biglia}

Universitat Rovira i Virgili. Facultat de Ciències de l'Educació. Departament de Pedagogia

barbara.biglia@urv.cat

\section{Resumen}

En el contexto actual de estructuración social organizada alrededor de la estratificación de los grupos sociales en una realidad de tránsitos continuos; la superación de la definición del sujeto «mujer» ha sido fundamental para lograr comprensiones sociológicas menos restrictivas. Sin embargo, las movilidades y los tránsitos, cuando impuestos, se acompañan frecuentemente por la experiencia de una precariedad emocional y vivencial aún poco estudiada. En este texto, se analizan algunos efectos de la condición fronteriza que experimentan algunas mujeres que tratamos de ejemplificar a través del relato de vida de Frida, cuya posición social experimenta una movilidad ascendente gracias a sus estudios y a su activismo político. Sus vivencias, no obstante, quedan muy marcadas por habitar al mismo tiempo mundos diferentes: clases sociales, géneros, identidad nacional, poseer/ser poseída, capitalismo/activismo. A través del análisis de su experiencia y del diálogo con la teoría, proponemos profundizar en los efectos de la interacción entre elementos vitales más estructurales (lugar de proveniencia, antecedentes familiares) y contingentes (experiencias de socialización primaria y secundaria, presiones sociales generizadas), así como la vivencia de habitar en espacios simbólicos fronterizos.

Palabras clave: subjetividades; fronteras; movilidad social; cambio social; precariedad vivencial.

\section{Abstract. Borderline experiences and the effect of social and class mobilities}

In the current context of a social structure organized around the stratification of social groups in a reality of continuous transits, overcoming the definition of woman and womanhood has been central to achieving a less restrictive sociological understanding of subjects. However, imposed mobilities and transits are often accompanied by the experience of emotional and existential precariousness that are still poorly studied. In this paper, we analyze some effects of the borderline condition experienced by women. We illustrate them through the story life of Frida, a woman who experienced upward social mobility through her studies and political activism, across a life trajectory that straddled different worlds: 
social class, gender, national identity, possessing/being possessed, and capitalism/activism. Through the analysis of her experience and a dialogue with theories, we further investigate the effects of the interaction between both structural (place of origin, family background) and contingent (experiences of primary and secondary socialization, gendered social pressures) vital elements on the experience of living on symbolic borderlines.

Keywords: subjectivities; borders; mobilities; vital precariousness

\section{Sumario}

1. Subjetividades, movilidades, barreras y fronteras para las mujeres de fin del siglo xx: apuntes teóricos contextualizados

2. Cuando la experiencia informa la teoría: de lo personal a lo político el paso es breve
3. Dibujando a Frida

4. Activismos: nuevos mundos $\mathrm{e}$ inflexiones

5. Vivir en las fronteras

6. De conclusiones a aprendizajes; de límites a fronteras

Referencias bibliográficas

\section{Subjetividades, movilidades, barreras y fronteras para las mujeres de fin del siglo XX: apuntes teóricos contextualizados}

El saber occidental se funda en la definición de dicotomías y jerarquías rígidas delimitadas por los extremos inalcanzables y antinómicos de la nada y el infinito (Placer, 1997). La misma construcción del sujeto completo y maduro (Lloret, 1997) se realiza a través de un yo que se define frente a las otras en un diálogo dirigido por normas y leyes, frecuentemente no escritas, que dictaminan lo permitido y lo imposible. Esta dinámica, que nos empuja a definirnos de manera coherente con los estereotipos del rol social asignado, está, además, enmascarada de autoconstrucción: «Te harás libremente como ha sido establecido para ti». De la misma manera, varias identidades, por su propia definición, nunca llegan a ser consideradas la expresión de sujetos de pleno derecho, con lo cual se crea una sensación de malestar o de inferioridad en quienes las habitan y tienen que conformarse con roles sociales subalternos siendo, por otra parte responsabilizadas por ello. En este sentido, por ejemplo, mujeres y personas con discapacidad funcional son frecuentemente infantilizadas, de la misma manera que sujetos de grupos étnicos minorizados o de clase social baja son animalizados. Es más, todas aquellas que no se posicionan claramente en un polo de las dicotomías (transexuales, afeminados, marimachos, envidiosas del pene, etc.) o que no se construyen como sujetos unitarios y unívocos (esquizofrénicas, histéricas, migrantes, precarias ${ }^{1}$, etc.) están sometidas a exclusión, marginación, rechazo y burla.

Sin embargo, la elección de una identidad frente a otra está socialmente controlada y limitada por normas y reglamentos que impiden autodefinirse.

1. Nos referimos, en este contexto, a la precariedad vivencial descrita en Biglia y Bonet (2014). 
Confines identitarios provistos de controles que los configuran como fronteras, que permiten la libre circulación sólo a sujetos privilegiados, tal como ocurre en el caso de las fronteras geográficas. Si bien varias personas retan los límites impuestos entre las categorías y transitan por los diferentes roles mostrando que los confines identitarios son permeables, el tránsito tiende a ser negando a las minorías excluidas, abyectas. De hecho, las geógrafas nos enseñan como las características de los sujetos (género, estatus social, lugar de residencia, etc.) (im) posibilitan su movilidad y de qué manera el tránsito, en lugar que difuminar los límites entre las categorías, puede llevar a la intensificación de las desigualdades (Sasunkevich, 2011) y a crear o reforzar los sentidos y las prácticas de género (Hanson, 2010). Sin embargo, si bien las fronteras se configuran, por un lado, en la materialidad de la barrera, por el otro, se conforman como intersticios, espacios de nadie, que pueden llegar a ser habitados por sujetos no normalizados. Aquí, algunas personas se sienten confinadas, reprimidas y sometidas en estos no-lugares, y aspiran a desplazarse hacia identidades reconocidas y dotadas de autonomía propia. Quienes quieren atravesar fronteras identitarias o de roles, no obstante, han de renunciar a algunas de sus características precedentes y conformarse con las del otro lado. Este tránsito, pues, no deja indemnes a las que lo realizan, como bien se explica en la metanarrativa Nieve Marrón y los siete detergentes (Subramaniam, 2000) ${ }^{2}$, en la cual la joven oriental Sneha, en el intento de ser aceptada y reconocida por la comunidad científica, va eliminando una por una sus especificidades hasta quedarse en nada y perecer.

Sin embargo, como se mencionaba anteriormente, es en esta misma frontera donde hay la posibilidad de construir otras realidades, experiencias desacralizantes y perturbadoras del orden constituido (Heyman, 2012). Quizás sea por esto que algunos sujetos deciden quedarse en las fronteras en lugar de cruzarlas, convencidos de que «A borderland is a vague and undetermined place created by the emotional residue of an unnatural boundary [...] a constant state of transition. Los atravesados live here [...] those who crossover, pass over, or go through the confines of the normal ${ }^{3}$ (Anzaldúa, 1987: 3).

La situación, como hemos visto, es extremadamente compleja. Algunos sujetos se quedan confinados en la frontera porque no se les permite atravesarla, mientras que otros deciden habitarla en lugar de situarse en uno de sus lados. En cualquiera de los casos, estar en la frontera, ser atravesado, se configura como una posición ambigua, de dificultades y posibilidades, así como el atravesarla y posicionarse en el otro lado. Además, como bien dice Elena Casado (1999: 86): «No solo "viajamos" atravesando las fronteras, sino que la propia identidad es un juego de fronteras móviles, productoras de significado, poderes, estructuras».

Esta vivencia identitaria se hace aun más compleja si tenemos en cuenta la interseccionalidad. Si, en los debates teóricos (Pujal, 2004), se subraya la

2. Agradezco a Alessandra Consolaro la indicación de esta increíble obra.

3. Se mantiene esta cita en sus idiomas originales para respetar la desafiante propuesta de Anzaldúa de mezclar el inglés con el castellano. 
importancia de reconocer que la pertenencia a diferentes categorías sociales nos lleva a asumir «identidades múltiples», éstas se presentan frecuentemente como capas en lugar de hacerlo como una intrincada red de vivencias, experiencias, deseos, frustraciones y prohibiciones. Así, mientras en algunas teorías se exalta la flexibilidad y la movilidad identitarias con una cierta banalización de la materialidad (experiencias, presiones sociales, condiciones de posibilidad, etc.), en otras se tiende a negar la agencia de los sujetos subalternos en sus construcciones identarias. Creemos importante romper esta dinámica y, en este contexto, indagar sobre los efectos de las materialidades en la construcción de las condiciones de posibilidad de los sujetos, al mismo tiempo que averiguar las consecuencias que tienen las elecciones de habitar o atravesar las fronteras identitarias en la cotidianidad y el bienestar de las personas.

Para ello, en este artículo, después de una breve introducción metodológica en la que explicaremos el sentido del uso de un caso individual para reflexionar sobre la contradictoria vivencia que nos proponemos analizar, presentaremos algunos elementos de la historia vital de nuestra protagonista: familia de origen, identificación generizada y relaciones de pareja, estudios y experiencias laborales. Seguidamente, analizaremos los cruces entre sus experiencias como activista y sus vivencias fronterizas. Finalmente, antes de presentar unas breves conclusiones, analizaremos la ambigüedad de la experiencia de vivir en espacios fronterizos.

\section{Cuando la experiencia informa la teoría: de lo personal a lo político el paso es breve}

Tal y como sugiere Nicolas Marín (2007), la vida de los individuos tiende a desaparecer en las narraciones de la historia política, así que las historias de vida devienen necesarias para recuperar el protagonismo de la acción humana. Éstas, se vuelven aun más relevantes por el reconocimiento de la olvidada, cuando no negada, experiencia de las mujeres. Por esto, durante la llamada segunda ola feminista, se popularizaron el análisis genealógico y la realización de biografías e historias de vida. Sin embargo, hay múltiples maneras de conceptualizar y utilizar estas técnicas.

En este trabajo, usaremos ${ }^{4}$ la story-life entendida como ejercicio de reflexión sobre lo social a partir de las vivencias personales (Mallimaci y Giménez, 2006), dado que nuestro fin no es recrear una historia particular para reconocer su existencia, como ocurría en los primeros trabajos feministas, sino aprender de una experiencia personal para entender mejor una realidad social. De alguna manera, proponemos un desplazamiento que lleve a reconocer el «sujeto mujer», no solo como protagonista de su vida, sino también como coproductor de realidades. La valiosa experiencia estudiada nos permitirá establecer un

4. El uso del plural en este artículo no pretende marcar una posición de impersonalidad u objetividad, sino reconocer la importancia de los debates que han llevado a confeccionarlo y que hacen difícil reconocer como única autora a la que lo firma. 
dialogo entre la narración oral del sujeto, la comprensión e interpretación de la investigadora que la escucha (Biglia y Bonet, 2009) y algunos debates teóricos relevantes. De esta manera, y coherentemente con el lema «Lo personal es político», intentaremos informar las teorías a partir de las experiencias.

En este camino, Frida, una profesional del tercer sector de unos cuarenta años y residente en el área metropolitana de Barcelona, es la persona que ha compartido sus vivencias con nosotras 5 . La recolección de su historia se enmarca en un proyecto de más amplio abasto dirigido por Julia Varela ${ }^{6}$, con el fin de recuperar y analizar la experiencia de mujeres en la España contemporánea para construir lo que en inglés se suele denominar Her-stories ${ }^{7}$. Más específicamente, el trabajo realizado con Frida forma parte de la sección en la que se han entrevistado sujetos nacidos entre las décadas de los sesenta y los ochenta, que han vivido su infancia o su juventud durante la transición española. En esta franja temporal, Ángel Gordo López ha dirigido su atención hacia mujeres de clase media, mientras que Pilar Parra ha recuperado la historia de las de clase popular. En línea con mis trabajos previos (Biglia, 2003, 2006; Zavos et al., 2005), en este contexto, mi cometido consiste en acercarme a la experiencia de alguien que ha transitado por los movimientos sociales y que, finalmente, en relación con la cuestión de clase, ha resultado situarse como nexo de conexión entre las mujeres que han compartido sus vivencias con Pilar y las que lo han hecho con Ángel. En el análisis propuesto, iremos reflexionando y/o resaltando aquellos elementos de la vida narrada de Frida que nos permitan ejemplificar las prácticas de poder generizadas y generizantes, así como interrogar sobre las maneras en las que las identidades están (re)producidas, resistidas y configuradas (Peterson, 2000). La importancia analítica de este elemento se debe a que los roles generizados mantienen una influencia muy temprana en la constitución del sujeto y el género (o quizás el sexo, según quien pregunte), lo que sigue siendo considerado un elemento fundacional del $\operatorname{ser}^{8}$. Así, nos interesa poner en evidencia la influencia mutua existente entre los significados culturales y las vidas psíquicas de Frida para analizar sus procesos de construcción identitaria, entendiendo esta última "como posibilidad de práctica, capacidad de acción» (Butler, 2001: 176). Sin embargo, siendo conscientes de que el género no es ni mucho menos la única categoría social a la que estamos adscritas, prestaremos

5. Frida es el pseudónimo escogido por la informante con la que hemos realizado tres sesiones de trabajo, todas en su casa, por un total de 6 horas y 10 minutos. Ella ha tenido acceso a la transcripción íntegra de la entrevista, ha revisado este artículo, ha aprobado su publicación y ha declinado la oferta de firmar como coautora. Aprovechamos para agradecerle su alta disponibilidad en todo el proceso.

6. Mujeres, cambio social y modos de subjetivación: Análisis sociológico de historias de vida de mujeres en la España contemporánea, Ministerio de Educación y Ciencia, I+D, convocatoria 2004-2007 (Ref. SEJ2006-04140).

7. El termino inglés histories ('historias') se puede descomponer en his (adjetivo posesivo masculino) y stories ('relatos'). El juego de palabras recuerda la importancia de las historias de ellas, las her (adjetivo posesivo femenino) -stories.

8. ¡Aun antes de que realmente seamos! Sobrepasa las posibilidades de este artículo reflexionar en profundidad sobre estas cuestiones ontológicas que merecerían una profunda atención. 
atención a aquellos factores de la vida de Frida que las feministas negras definirían como interseccionales (Crenshaw, 1989). En este sentido, conviene hacer una aclaración teórica: el uso que haremos del termino interseccional no quiere restar importancia a las particularidades de las experiencias de la colectividad negra o "desarticular la interseccionalidad desde sus raíces teóricas políticas y metodológicas, substituyéndolas por reificantes formas esencialistas de identidades políticas y/o modelos de investigación dominantes" (Alexander-Floyd, 2012: 18-9), sino, muy al contrario, aprendiendo de su peculiaridad, establecer una política de alianzas.

La alta capacidad autorreflexiva de Frida, marcada específicamente por el ejercicio de la misma en la práctica militante y por su relación ambivalente con el feminismo, nos ha dotado de un material extremadamente elaborado y complejo que ha estimulado nuestro interés hacia el trabajo analítico sobre los efectos de la condición fronteriza que viven determinadas mujeres.

A través de las vivencias de nuestra informante, nos proponemos dirigir una mirada crítica, tanto hacia los procesos de subjetivación generizada, como hacia ciertas simplificaciones de las teorías posmodernas que ven solamente las potencialidades de las fragmentaciones de los sujetos, descuidando la experiencia cotidiana de las personas. No nos interesa tanto proponer una interpretación de la vida de Frida, como utilizar las descripciones de su saber experto para corporeizar debates teóricos que, en literatura, quedan frecuentemente convertidos en hechos abstractos.

\section{Dibujando a Frida}

\subsection{La (sagrada) familia y la llamada socialización primaria}

Los padres de Frida pertenecen a los que se suelen denominar migrantes internos (con movilidad rural-urbana), provenientes de familias campesinas del sur del Estado español con escasos recursos económicos. Su situación es compartida por un elevado número de personas. Fue exactamente en las décadas de 1960 y 1970 cuando se produjo la migración más numerosa desde otros lugares del Estado hacia Cataluña (Pascual et al., 2002).

El padre, en cuanto hijo mayor de su familia, estaba destinado a heredar la tierra y la casa del pueblo, sin embargo, cuando cumplió los 30 años, decidió romper la tradición familiar y, tras una fuerte pelea con su progenitor, se mudó a Barcelona. En la Ciudad Condal, después de realizar varios trabajos precarios, encontró estabilidad como obrero en una fábrica, compró un piso y volvió al pueblo para "traer a su novia», con la cual se casó en Barcelona. A los nueve meses, nació Frida, dos años después, el primer hermano y, en un segundo momento, un nuevo "paquete de hermanos», todos varones, que tienen 10 , 12 y 14 años menos que la primogénita. El último parto trajo complicaciones de salud a la madre, que, por otra parte, tenía que cuidar de un hijo de 2 años y otro de 5, así que Frida se hizo cargo del hermano menor: «El pequeño fue mi paquete». 
A nivel educativo, hay que destacar que ambos padres tienen una formación primaria, si bien la madre, "la lista de la clase», lamentaba mucho no haber podido seguir con los estudios. Por lo que concierne a las relaciones de género en el seno de la familia, Frida cuenta que, en casa de la madre, era la abuela quien mandaba, y en la del padre, el abuelo hizo de "Padre Padrone» hasta que, después de pelearse con toda la progenie, la tía monja se convirtió en figura de autoridad familiar.

Las relaciones de poder en casa de Frida son intrincadas, pues, si bien el padre "manda de cara afuera, los hijos saben que manda la madre». Sin embargo, el padre, frecuentemente ausente por cuestiones de trabajo, ejerce ocasionalmente su control a través de castigos corporales, y la madre, que se dedica completamente al cuidado familiar y que «nunca jamás dedicaba tiempo a sí misma o a su feminidad", ejercita su control más bien a través de chantajes emocionales. No obstante, según nos cuenta Frida, esta reproducción de roles tradicionalmente generizados se va difuminando con el transcurrir de los años gracias al contacto con nuevos modelos relacionales, hasta el punto de que el padre, al caer la madre enferma, se transforma en el cuidador de su mujer.

El padre de Frida, en la infancia, la trata con frecuencia como si fuera un niño: le encarga trabajos de bricolaje y llega a exponerla delante de una vaquilla, conjuntamente con todos los coetáneos varones, en una fiesta popular. El análisis que Frida nos presenta de esta actitud es que se trataba de un intento, además exitoso, de hacerla fuerte. Al mismo tiempo que juega «con amigas a comprar, a cocinar, a hacer de mamá», no desdeña los juegos físicos con los chicos y, con sus hermanos, tiene una relación que incluye la libre expresión de la agresividad. Ella se adapta a las formas de relación masculinizadas en la infancia, y sus hermanos, aceptando su autoridad como "madre sustitutoria», se exponen a un modelo de femineidad no estereotipado, por lo que, de adultos, «son más dulces y femeninos de lo que es habitual en nuestro entorno».

En general, Frida recuerda muy poco de su época de juegos, pero menciona la fascinación que tenia hacia «mujeres distintas»: las que usaban la violencia, «como las polis de las teleseries», o las que eran «malas, brujas».

\subsection{Identificaciones de género y relaciones de pareja}

Si la infancia, como acabamos de ver, está marcada por una no aceptación de los roles femeninos clásicos y por una fascinación hacia las mujeres fuertes y poco corrientes, como la madre soltera y activista de una compañera del instituto, en cuanto empieza a desarrollarse físicamente, Frida experimenta una fuerte atracción hacia la identidad femenina estereotipada. Tal y como propone en su estudio exploratorio La Parra (2000), el pasaje a la vida adulta es un momento particularmente delicado en la configuración de la identidad de género. En esta época, las resistencias de las jóvenes a reconocer las discriminaciones de género parecería ser muy alta (Biglia y Velasco, 2012), y Frida no es una excepción en este sentido. Al poco de tener la regla, y al darse cuenta 
de que su cuerpo es objeto de miradas, experimenta una sensación de placer por el poder de atracción que provoca.

A los 11 años, estaba jugando a mamás y a papás, a hacer comiditas con mis amigas, y de repente, al año siguiente, yo ya era una chica con tacones, y los tíos me miraban, y los tíos me decían cosas; [...] exageraba mi feminidad mucho y estaba en plena potencia.

Es en esta época cuando los progenitores comienzan a controlarla y a reprimirla. El padre le repite continuamente: "Como vengas con un bombo, te mato». Esta amenaza se produce en un contexto de falta de educación sexual total, hasta el punto que descubre los tampones gracias a la compañera de su hermano (menor que ella).

Poco después de su florecimiento sexual, inicia sus relaciones de pareja, muy marcadas por los roles de género y la búsqueda de chicos muy masculinos y fuertes. Se deleita al sentirse deseada en un juego peligroso en el que, si bien no goza plenamente de la sexualidad, disfruta del poder de controlar el deseo masculino de poseerla. El descubrimiento de la masturbación (a los 14 o 15 años) es vivido como algo pecaminoso, algo que no se puede hablar con nadie, sentimiento que no se modifica hasta muchos años más tarde, con el descubrimiento del feminismo.

Durante su primera relación de pareja, «era la novia de, me pintaba los morros, me colocaba los tacones, [...] y no abría la boca». Sin embargo, en un contexto social en el que el uso y el abuso de heroína diezman a las y los jóvenes, él, ejerciendo su rol de varón controlador, la mantiene alejada de la droga: «Ni la probé, ni dejé de estudiar, porque él no quería que la probara, porque él no quería que yo dejara de estudiar». La relación con este chico se resquebraja más tarde, cuando ella empieza a adquirir nuevas actitudes generizadas, no obstante, durante largo tiempo, él seguirá representando el vínculo con su mundo «barriobajero».

Así que Frida llega a la universidad con un aspecto y una actitud fuertemente marcados, tanto por los roles de género como por los de clase: «Yo soy la Juani, [...] una niña de barrio [con] esos pantalones, ajustados, los tops, los tangas, los tacones, [...] unos aros en las orejas y después cuelgan los loros, súper grandes, súper maqueaditas, ese look.... quinqui [...] muy lolai». En esta época, empieza a tener su primera relación con un amigo de la universidad, menos desigual que la anterior, pero siempre marcada por los roles de género. Se promete con él muy pronto. El sueño dura hasta que lo encuentra en la cama con otra mujer, cosa que vive como una fuerte traición y que la desilusiona mucho, hasta el punto de hacerle cambiar su idea sobre las relaciones, pero también sobre los varones en general.

Frida va modificándose como persona y asumiendo una identidad de género menos estereotipada (gracias a los encuentros a los que haremos referencia en el próximo apartado), al mismo tiempo que sus relaciones se hacen más complejas y se abre a experiencias no monogámicas consensuadas. De hecho, Frida suele tener como parejas a amigos de los grupos en los que se mueve, 
con los cuales, una vez acabada la relación propiamente dicha, mantiene un fuerte vínculo con un alto grado de intimidad. Ella asocia el tener múltiples relaciones con la necesidad de encontrar diferentes "cosas» en las parejas, con una continua sensación de insuficiencia, así como con una «incapacidad de romper con el pasado». En diferentes momentos de su narración, cuenta que no sabe estar sola, y que por esto busca continuamente parejas. Hay que destacar, finalmente, que los compañeros que tiene a partir de esta época son generalmente más jóvenes que ella (quizás quiere tener el control después de las fallidas experiencias anteriores), y que, con el pasar de los años, acaba sintiéndose atraída por sujetos de masculinidades cada vez menos estereotipadas.

\subsection{Educación}

Frida se sitúa en una generación que «se ha educado en pleno auge de las escuelas de masas» (Fachelli y Planas, 2011: 1284). No obstante, como vivía en un barrio marginal, no fue «al colegio hasta mayor: me enseñó a leer mi madre. En el barrio, no había escuelas públicas, ni servicios, y muchos migrantes, así que hubo muchas luchas para que abrieran escuelas públicas, al final consiguieron dos». Asiste a una «academia privada» mixta: un negocio familiar en que los estudiantes estaban «hacinados y con Franco encima de la cabeza y rezando. Si hablabas mientras rezabas, te ponían cinta aislante en la boca». Allí, a pesar de sus buenos resultados, tuvo que hacer clases de repaso por la presión de la escuela. Ella vivió esta situación con «un fuerte sentimiento de injusticia mezclado con inseguridad (¿igual no era tan buena como pensaba?)». Poco después de la desaparición de Franco, y a raíz de un problema de vista debido a las insalubres condiciones de la academia, Frida hace su ingreso, en cuarto de EGB, en una escuela pública. Allí, «sin retrato de Franco ni crucifijo», las relaciones de poder eran menos marcadas. No obstante, «había dos grupos distintos bien separados: las listas y las que no lo eran».

Con una formación inicial muy pobre, Frida, hija de su tiempo, estaba convencida de la importancia de la educación reglada para la movilidad social ascendente (Fachelli y Planas, 2011): «Yo también, tenía muy claro que, para mí, los libros eran importantes, estudiar era importante, que eso era lo que me podía sacar de [...] mi rol de clase». Esta impresión se vio reforzada más tarde, cuando, trabajando como camarera, «me di cuenta de que yo tenía que estudiar para no ser una obrera, porque yo eso no lo podía soportar» ${ }^{9}$.

Quizás por no haber podido estudiar, la madre de Frida también estaba empeñada en que su hija tuviese dicha oportunidad, mientras que la opinión del padre era distinta:

[...] no dudaba de que yo pudiera, pero decía: «¿Para qué? ¡Si se va a casar! ¡Y es un dinero tirado!». No obstante, no hubo negociación, [...] yo simplemente

9. Sin embargo, no era consciente de que, tanto el conseguir una titulación universitaria (Fachelli y Planas, 2011), como el obtener una buena inserción laboral gracias a ella (Lindely y Machin, 2012), seguía siendo un elemento directamente relacionado con la formación de los progenitores y, teniendo en cuenta la época, con la clase social de origen. 
iba a seguir estudiando [...] si mi madre decía que yo estudiaba, yo estudiaba. Eso no se ponía en cuestión.

La madre empuja, por tanto, a Frida para que estudie, pero no influye en la elección de carrera cuando llega a la universidad, tal como ocurre unos años después con las chicas protagonistas del trabajo de La Parra (2000). De hecho, a diferencia de algunos de sus compañeros de universidad, que, provenientes de la elite catalana, disponían de un capital social y cultural mucho más alto, los padres de Frida no le pudieron «servir de ayuda para escoger una carrera ni para ayudarme a matricularme ni para ayudarme con asignaturas, todo eso era algo que se les escapaba completamente». Esto le dio mucho margen de autonomía, al mismo tiempo que la cargó de responsabilidades: «lo que estábamos decidiendo caía sobre nuestras espaldas, porque nadie más iba a decidir por nosotros». Estudia, por lo tanto, la carrera que había escogido de pequeña, cuando a raiz de los revuelos provocados por la muerte de Franco y el golpe de Estado, decide ser periodista "porque los periodistas tienen poder", el poder de ser escuchados y de crear alboroto en las casas:

[...] la rutina se había roto, mi tía lloraba, había que mirar la tele, la tele no daba programación habitual, entonces ese día pues yo recuerdo como que algo estaba pasando, y algo que afectaba mucho a todo el mundo. [...] yo escribí aquella semana: «Voy a ser periodista».

La universidad fue una etapa de apertura a nuevas realidades: «sobre todo los primeros cursos era un poco aventura $[. .$.$] geográfica y emocionalmente»,$ pero también de choques. Se siente por primera vez perteneciente a un grupo de migrantes y vive en su piel las diferencias de clase. Socializada y educada en castellano, al llegar a la Universidad Autónoma de Barcelona, descubre que «en Cataluña se habla catalán, y que existía Cataluña [...] ¡Si todo el mundo habla catalán! [...], era otro mundo realmente». Ella y sus amigos son identificados como los migrantes, los barriobajeros y se juntan preferentemente con otros jóvenes de condiciones similares. Algunas compañeras y profesores les miran raro, pero, por lo general, "no nos sentíamos rechazados ni nada», sin embargo, se sienten rodeados de un cierto paternalismo: «Fijate estos chicos hijos de andaluces que han llegado hasta aquí». Así, Frida vive en su piel las diferencias de clase: «Los hijos de determinada gente [...] podían perder el tiempo, podían dedicarse a vivir la vida loca [...] pero nosotros teníamos la obligación de hacer algo con nuestros estudios». Sin embargo, es trabajando de niñera en verano cuando se dio "perfecta cuenta del trato diferencial, casi esclavista, que se les daba a las filipinas y gallegas internas y del trato preferente que teníamos las cuidadoras de niños universitarias».

\subsection{Experiencias laborales}

De acuerdo con su conciencia de clase, la motivación para estudiar era fuerte. Progresar y conseguir un trabajo mejor del que habían tenido sus padres era sentido como una obligación. De hecho, según ella, la mayoría de la gente de su 
instituto escogió carreras útiles porque eran hijos e hijas de obreros, y el estudio era entendido como una posibilidad de movilidad social. Frida disfrutó de becas, pero, dado su alto sentimiento de responsabilidad, asumió muy pronto trabajos temporales y de tiempo parcial hasta que en «cuarto y quinto prácticamente no fui a clase $[\ldots]$ trabajaba por las mañanas y estudiaba por la tarde». Este ritmo se intensificó cuando el padre abrió una panadería: «Estaba en medio de un mercado, con mi bata blanca y levantándome a las seis de la mañana».

$\mathrm{Al}$ acabar la carrera, empieza un postgrado y, gracias a un amigo, consigue un trabajo temporal como administrativa en la Universidad. Su dedicación gusta a los jefes, que le van renovando contratos y subiendo de categoría durante cuatro años seguidos, hasta que pierde la posibilidad de consolidar su plaza por un problema laboral. Recuerda que, por lo general, hay buen clima entre los miembros del equipo, pero las relaciones íntimas que mantiene con algunos compañeros tensionan el ambiente. Al terminar esta experiencia, y como se le agota el paro, decide abandonar la idea de volver a estudiar y acepta un trabajo de comercial en el sector turístico. Empieza atendiendo al teléfono, pero llega a ser directora de marketing debido a su alta dedicación y al sentimiento de que "es absolutamente imprescindible que yo lo haga lo mejor posible». Los espacios de trabajo estaban divididos por género:

[...] en la oficina, eran todo chicas y el resto del personal eran hombres y entre los dos grupos había como una especie de barrera. Cuando nosotras bajábamos a la cocina [...], las conversaciones se cortaban. Al mismo tiempo, las mujeres percibían un mundo salvaje masculino del cual querían mantenerse al margen.

Finalmente, las relaciones se vuelven insoportables y Frida, que ejerce por un periodo un rol de mediadora entre los dos mundos, decide dejar el trabajo, al encontrar otra ocupación en una organización no gubernamental, en la que sigue en el momento en que se realiza la entrevista.

\section{Activismos: nuevos mundos e inflexiones}

El «cura rojo», como ella misma lo llama, es una persona que ha ejercido una gran influencia en la vida de Frida. Cuando tiene alrededor de 17 años y todavía se describe como «la novia de», es él quien la estimula a verse como una persona completa, a tener un papel autónomo. Intuyendo que «tenía posibilidades, que me tenía que sacar un poco de aquel ambiente», apuesta por ella: «Me potenciaba, me animaba a decir cosas, a expresar mi opinión».

En esta época, si bien en el tiempo libre Frida continúa siendo «la Juani, que sigue a su novio sin hablar en la discoteca, pintándose los labios como a él le gusta», en la parroquia, se trasforma en la pequeña líder intelectual que hace enmudecer a su pareja.

La otra gran influencia que Frida recibe de este encuentro es el acercamiento a espacios de compromiso social que la llevarán, más tarde, a la militancia. Esto le ayuda, además, a reconocer una conciencia de clase latente: 
Yo eso lo tenía clarísimo, que yo tenía menos derechos, por haber nacido en determinado barrio, por ser hija de determinada gente, y eso es lo que ha dirigido mi lucha política [...] durante mucho tiempo.

Finalmente, cabe destacar que es también en la parroquia donde se forma un grupo de amigos y amigas, con los cuales, pasando los años, Frida compartirá gran parte de su militancia, así como sus espacios de vida: "Nuestra formación política fue esa de la Iglesia obrera y roja, [...] donde nos dieron una estructura política muy clara, muy comunista».

A sus 25 años, entra en contacto con la teoría de la liberación y se siente fascinada con su ideario. Su activismo se desplaza entonces de la lógica del voluntariado a la de la acción política. Así, motivada por conocer en primera persona el trabajo de los jesuitas, cruza por primera vez fronteras geográficas y se va, con su amiga del alma, a una brigada de trabajo destinada a El Salvador. Inaugura, de este modo, un activismo internacionalista que seguirá en el tiempo. De hecho, Frida y sus amigos, después de montar un grupo de apoyo a enfermos terminales de sida, fundan otro de soporte a Nicaragua, ambos en el seno de la estructura católica.

Sin embargo, es en esta misma época cuando Frida y sus amigos conocen el movimiento okupa. La primera toma de contacto se produce cuando intentan crear redes locales para proyectos de solidaridad internacional. Entre risas, Frida cuenta el choque del primer encuentro: entra en el centro social okupado, en el cual «estaban todos fumándose sus petas», y se presenta como miembro de «un grupo de solidaridad de la parroquia». Los presentes la miran con sorpresa y no parecen entender el porqué de su visita. Sin embargo, Frida, que ya había experimentado en la universidad el contacto con realidades lejanas, "tenía muy claro que tenía que investigar, que había que saber, y que esa gente a mí me interesaba conocerla», así que, haciendo frente a ese desconcierto, entabla relaciones y reconoce que, en realidad, "nos acogieron muy bien y nos respetaron mucho siempre».

Envuelta en una realidad en la que las reglas no son tan rígidas y la alegalidad flexibiliza la posibilidad de realizar acciones políticas, se le abren nuevas perspectivas:

Conocer todo el tema okupa o todo el tema zapatista que era puro romper las reglas. [...] Sobre todo de cuestionar precisamente muchos temas de jerarquía de estructuras [...] Las maneras también de relacionarnos en la militancia, pues todo el rollo más cultural y más libre [...] de la relación con el sexo, con la política $[. .$.$] bueno todo eso fue un descubrimiento absoluto.$

Por un tiempo, el grupo al que Frida pertenece sigue enmarcado en la parroquia e intenta conjugar las dos realidades, introduciendo en ella debates procedentes del entorno más radical. Finalmente, deciden independizarse de la estructura eclesiástica y mantienen activos únicamente vínculos personales con la parroquia y con el cura. 
Al poco tiempo de entrar en contacto con los okupas, Frida empieza una relación con uno de los miembros más carismáticos del colectivo, por el cual siente un fuerte respeto intelectual. Y, si bien «el okupa y la cristiana» eran «la atracción de feria», esta relación y la alta implicación del grupo de la parroquia en las actividades del centro los llevó pronto a ser reconocidos como miembros del movimiento. En esta época, Frida experimenta con relaciones no monogámicas reconocidas; además, conoce varias chicas que considera «ejemplo de fortaleza y de valentía [...] porque iban desnudas siempre por la vida y porque se enrollaban con cualquiera y, sobre todo, porque, en el momento de los desalojos, se colgaban de los cables igual que ellos».

Frida, que, dentro del movimiento, asume un rol de comunicadora (de texto), se ve envuelta en una situación esquizofrénica entre su trabajo de comercial y su activismo político. Como ella misma señala, en el trabajo:

[...] en Noche Vieja hacíamos cenas especiales, llenaba el local con 100 personas, que pagaban $25.000,30.000$ pesetas [y], a la mañana siguiente me iba a la calle, a un chiringuito de los que se iban a Nicaragua para sacar 3.000 pesetas.

La relación de Frida con el feminismo no es menos contradictoria que la que mantiene con otros ámbitos de su vida. Por un lado, muestra una inconformidad temprana con las limitaciones de su rol generizado y responsabiliza al padre de todas sus desgracias, "porque era autoritario, machista, porque no me dejaba estudiar ni me dejaba salir». Por otro lado, si bien tiene buenas amigas, reconoce que «durante mucho tiempo, mis mejores amigos eran tíos», quizás porque considera "que los hombres son más fáciles de controlar», de hecho, ha experimentado «muchas relaciones de mal rollo con tías». Finalmente, en algunos momentos, parece considerar a las mujeres más responsables de poner en práctica tecnologías de género: «Ahora sé que la que me ha vuelto loca ha sido mi madre, la que me estaba obligando a un doble rol era mi madre [...], mi padre en cierta manera hacía lo que le tocaba hacer».

En el plano político, declara que su primera y fundamental lucha ha sido la de clase y parece haber relegado, por mucho tiempo, el trabajo contra las discriminaciones de género a un plano mucho más privado. En los últimos años, esto ha ido cambiando, aunque tiene:

[...] la sensación que yo no quería, pero todo mi alrededor se había dispuesto para que yo entrara [en el feminismo]: yo no quería echarme un novio que supiera de género y que se dedicara a eso, no quería hacerme amiga de chicas que se dedicaran a eso y, sin embargo, bueno, me he ido encontrando con eso [...] si la vida me ha ido llevando hasta allí, [...] pues por algo será.

Este encuentro no buscado con el feminismo, o incluso resistido, se configura, sin embargo, como una fuente de crecimiento que le permite dotar de sentido muchas de sus experiencias y reconocerse en la vida de otras mujeres: 
En el momento en que yo me encuentro con las teorías feministas, con todo el tema de género, pienso: «Madre mía, pero si esto le ha pasado a montones de mujeres antes que a mí. Si yo no soy la única. Si todo esto estaba escrito desde hace un montón de años». Y es mucho de reconocimiento.

No obstante, sigue siendo escéptica respecto al feminismo, en cuanto afirma haberse encontrado más con teóricas que con activistas y haber conocido pocas feministas de clase baja. Así, por un lado, muestra una gran fascinación intelectual por dicho movimiento, cuyo encuentro considera que le ha cambiado la vida, y, por otro, mantiene una cierta resistencia hacia él en cuando siente que la aleja de su primera lucha: la lucha de clases.

\section{Vivir en las fronteras}

La artista y activista mexicana Frida Kahlo representa muy bien, en su Autorretrato en la frontera entre México y los Estados Unidos (1932), la vivencia de permanecer entre mundos diferentes.

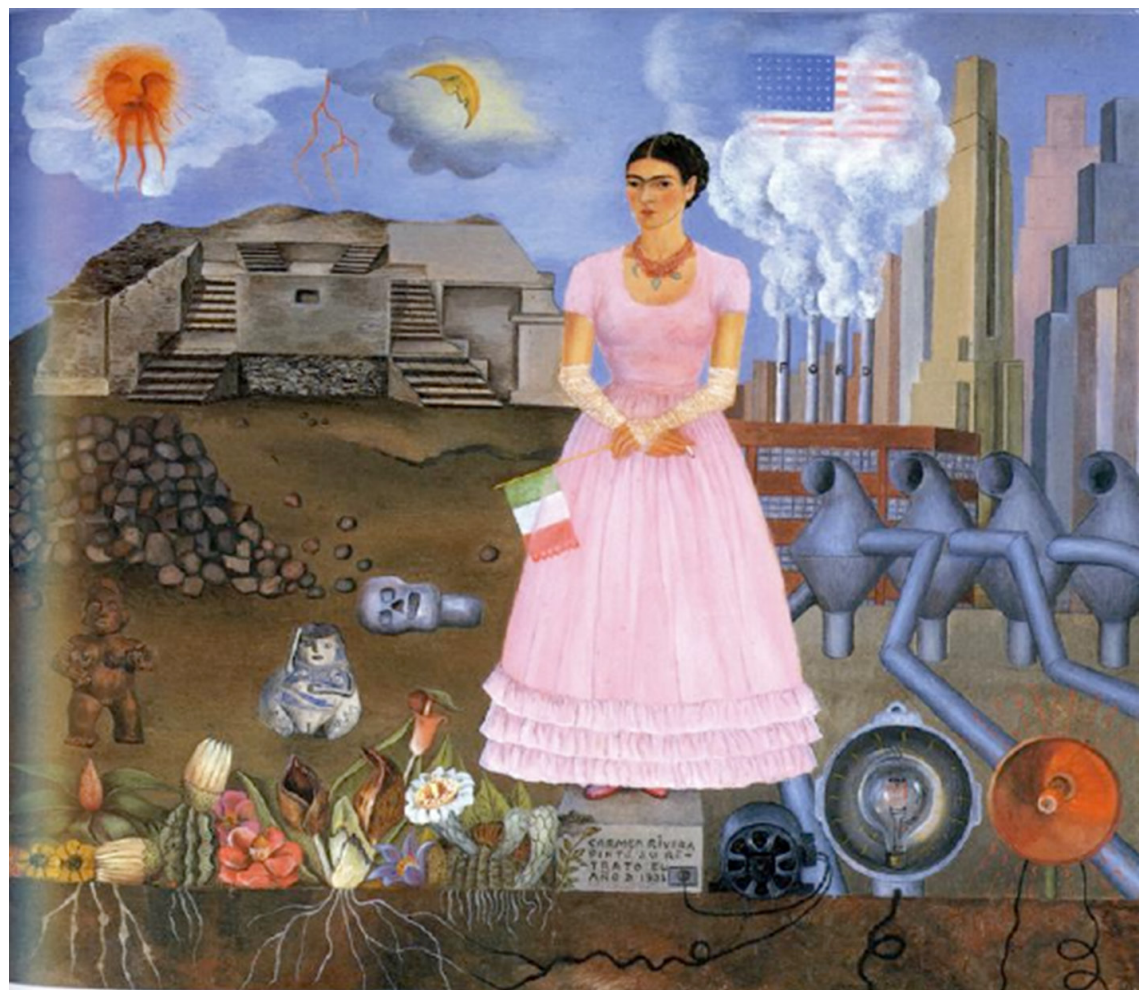

1. Self-Portrait Along the Boarder Line Between Mexico and the United States (Khalo, 1932) 
Una sensación similar a la de la pintora parece ser la que experimenta «nuestra» Frida:

Yo me siento una persona de frontera, absolutamente [...] a nivel de identidad sexual entre comillas, de identidad de clase, de identidad cultural, nacional [...] lo que no entiendo es solo ser de un sitio, solo ser de una manera [...] puedo construir una identidad muy fuerte, entonces, bueno, a mí me dicen desde ser roja, feminista, creyente, tener una identidad de clase muy marcada [...], sentirme muy maternal y al mismo tiempo muy masculina, todo eso [...] igual que sé que nunca voy a dejar de ser hija de campesinos, también sé que [...] leo cosas de élite [...] intelectual.

Tal y como hace Gloria Anzaldúa (1987), y muchas otras mujeres con ella, Frida parece preguntarse todo el tiempo, a través de su cuerpo, de sus acciones, de sus decisiones, pero también de sus reflexiones: «Who am I?», "¿Quién es este sujeto que habita las fronteras?».

Escuchando y leyendo su historia, se tiene la sensación de que, en algunos casos, es ella la que escoge estar atravesada, quedarse habitando la frontera. Por ejemplo, si bien sus estudios y su situación profesional le permitirían identificarse con la clase media, no quiere dejar de lado su origen de barrio. Reitera constantemente la importancia de no renunciar a su pasado, de no esconder su procedencia, de no pasar por la experiencia de «lavado» de Sneha (Subramaniam, 2000). Apuesta, por el contrario, a que se reconozca y se valore su identidad híbrida.

En otros casos, en cambio, parece que el posicionamiento en la frontera es debido más a coyunturas estructurales que a elecciones personales. Por ejemplo, como muchas otras mujeres, Frida crece con la idea de tener que conseguir las metas masculinizadas (negadas a las mujeres), sin por ello dejar de internalizar los mandatos de feminidad (cuidado de los demás, ocupación siempre de todo y de todos). Esto la lleva a asumir una pose de mujer fuerte, sensual, liberada, que puede con todo y con todos, bien representada en esta imagen que ha realizado el colectivo Sexyshock (2007) para mostrar la condición de muchas mujeres de nuestra época.

Sin embargo, estas peticiones y aspiraciones sociales no son muy nuevas, como bien muestra la descripción de Sega en relación con mujeres que han vivido a caballo entre los siglos XIX y XX.

Mujeres que, en el deseo de construir su subjetividad sin constreñirla a los límites socialmente impuestos al sexo femenino [...], rompen con la tradición del modelo materno para aspirar a un mundo más grande, más rico, capaz de acoger su deseo de libre búsqueda identitaria, habiendo recibido una formación más compleja que las autoriza a diseñar un futuro substraído al destino de esposa y madre, que entrará rápidamente en conflicto con el hecho de ser mujeres. (Sega, 1995: 28)

Conflicto permanente, interno, entre los roles generizados que no pasa por los cuerpos sin dejar rastros. Frida, por ejemplo, nos cuenta como, en el intento 


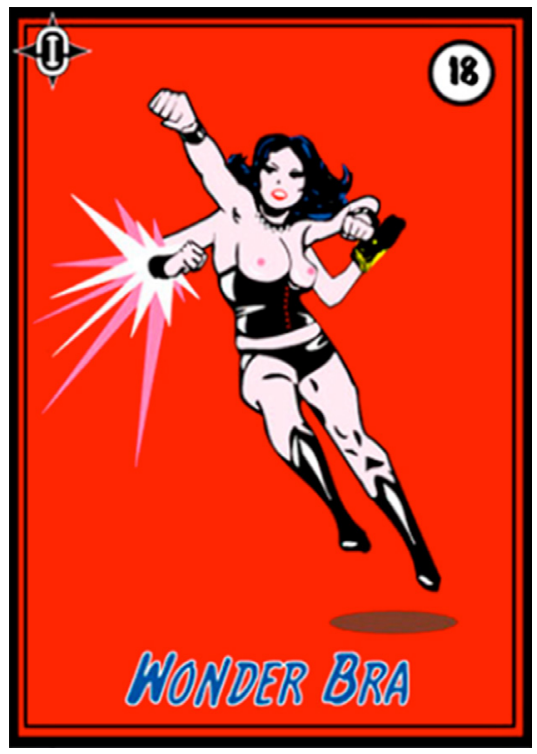

2. Wonder Bra. Meglio battere che combattere. (Sexyshock, 2007)

de conformarse con el mandato femenino de control de la agresividad, llega a descargarla hacia sí misma.

Esta dureza, esta tensión permanente a mí también me hace daño [...] esta violencia tengo que reprimirla, reconducirla, reorientarla [...] desde que empecé a racionalizar esto y dejé de ser violenta [...] empecé a tener problemas de salud, a somatizar mi histeria, mi rabia.

Cuando va a un psiquiatra, por recomendación de una amiga médica preocupada por su incesante pérdida de peso, se resiste a aceptar el diagnóstico de depresión que le hace: «No tengo una depresión, porque los que están deprimidos lloran, están tristes, están en la cama, no tienen ganas de hacer cosas y a mí no me pasa nada de eso, a mí lo que me pasa es que no puedo tragar». ¿Qué es lo que no puede tragar?

Frida lo describe como una crisis de crecimiento, sin embargo, escuchándola, se tiene la sensación de que no podía resistir todos los dobles vínculos y contradicciones a los que estaba sometida. Ser hiperdedicada en un trabajo con el cual se sentía éticamente inconforme, ser independiente y fuerte pero cuidadora y cariñosa, mantener roles ambiguos en las parejas:

Era la crisis existencial, ¿̨qué [...] estoy haciendo con mi vida?, ¿qué [...] estoy haciendo en este trabajo?, ¿que [...] estoy haciendo con mis parejas?, [...] mi sentimiento existencial de fracaso [...], ¿qué [...] estoy haciendo yo aquí? 
Sus palabras nos hacen pensar que quizás estaba harta de actuar como la supermujer que lo puede todo, la que cuida pero no necesita ser cuidada. El elemento del cuidado queda, de hecho, patente cuando nos explica: «Estaba en mi peor momento de ansiedad y depresión, me estaba empastillando y tenía algunos problemas serios, [...] de movilidad, por ejemplo [...]». Y llegaba a extremos de llamar a su pareja para que la fuera a buscar al trabajo "porque soy incapaz de llegar a mi casa». Vemos aquí como Frida se permite pedir atención y cuidado solo porque está «enferma», debido posiblemente a haber somatizado su malestar más profundo. Podemos peguntarnos si esta "depresión» no es, por tanto, una forma de rebelión contra la realidad y los mandatos sociales, muy parecida, aunque menos radical, a la que, unos años después, sufrirá su madre:

Mi abuela tenía un alzheimer [...] terminal, [...] y mi madre se estaba dejando la piel cuidándola. [...] Estábamos mi abuela, mi madre y yo. Mi abuela empezó como a ahogarse, [...] mi madre, que siempre ha sido la logista, la que ha organizado todo, se desesperó, se desorganizó, se descontroló. [...] Al año siguiente, tenemos otro diagnóstico de alzheimer para mi madre. Mi madre, en ese momento, plegó [...], desconectó de su propia responsabilidad, y dijo: "Yo ya he acabado, te toca a ti».

También podemos ver las similitudes entre esta experiencia y la que viven las numerosas mujeres diagnosticadas de fibromialgia (Barker, 2005).

Sin embargo, por lo general, Frida, como muchas otras mujeres, no busca apoyo externo y se enfrenta, de manera individual y privada, a los mandatos de género. Parece ponerse continuamente a prueba y no permitirse ser débil. Decide, por ejemplo, irse a Nicaragua sola, en plena crisis:

Estaba absolutamente condicionada físicamente por mis fobias, por mis ansiedades $[\ldots]$ me encontraba muy mal, muy insegura [...] pero hubo cosas que no dejé de hacer aunque con mucho miedo. Yo toda la vida he tenido mucho miedo a muchas cosas, pero también he sentido que era muy malo que ese miedo no me dejara hacer cosas.

Como vemos, Frida, muy hábil en hacer elaborados análisis de su realidad, sigue en la práctica con la lucha individual por ser reconocida. Esta misma actitud la ha llevado a ganar a pulso reconocimiento en el mundo masculino, cosa que le vuelve como un bumerán a la hora de establecer relaciones de pareja heterosexuales (recordamos que otra de las fronteras de Frida es la relacionada con las sexualidades anormativas). De hecho, tiene la sensación de que los amigos que querían ligar con ella lo hacían para alcanzar un trofeo, pero que luego no la aguantaban: «[... ] les gustaba esta tía poderosa, pero luego eran incapaces de gestionar esto en la intimidad [...] conmigo se enrollan, a mí me desean, les gusto mucho, pero se casan y tienen hijas con otras». Quizás se deba, también, a que Frida, acostumbrada a un nivel de autoexigencia extremadamente alto, no pide menos a los demás. De nuevo, esta experiencia no es aislada, muy al contrario, parece ser compartida por mujeres de diferentes 


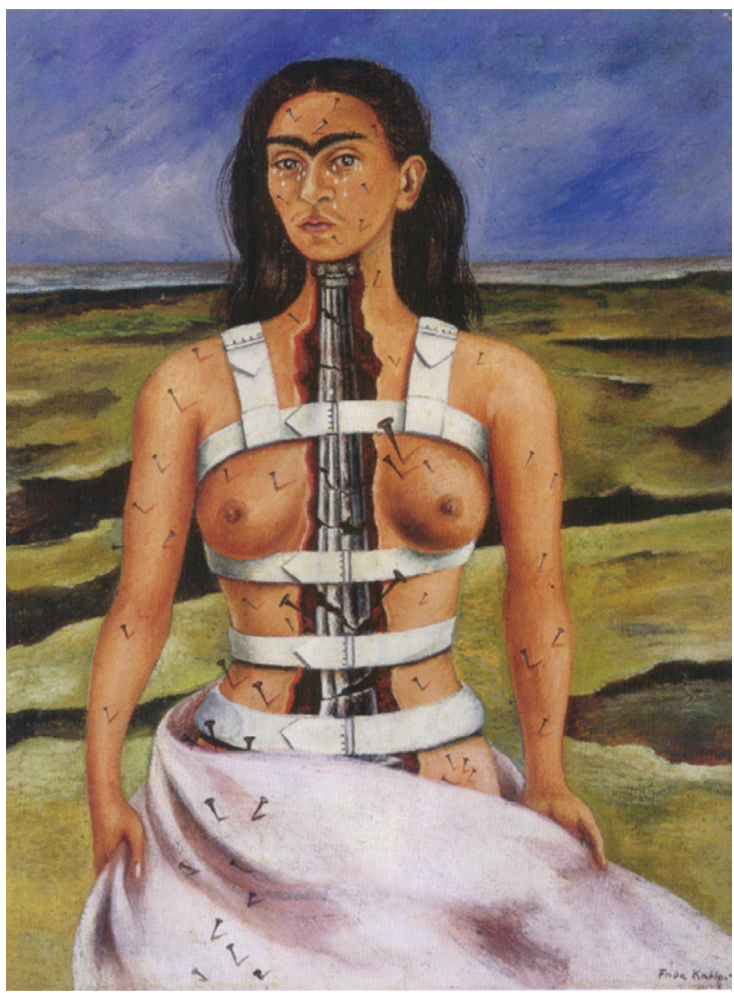

3. The Broken Column (Khalo, 1944)

épocas. El hijo de Regina García López, la Asturianita, explica que su madre, nacida a finales del siglo XIX,

[...] tenía una personalidad arrolladora. Era un cerebro y los hombres en aquella época querían ser tutores de las mujeres [...] Lo mismo que [a mi padre] le atrajo de ella fue lo que les separó. Tengo la impresión de que mi padre se sentía desbordado por ella. (Junquera, 2012) ${ }^{10}$

Así que, como hemos visto, Frida es un ejemplo de mujer atravesada por deseos propios, construidos e impuestos, frecuentemente contradictorios, que la hacen vivir en la frontera, e intenta solucionar de manera individual las contradicciones a las que se enfrenta. Sin embargo, "las situaciones de quiebra nos colocan ante la certeza de que la potencia en la que se basa el ideal de independencia es una potencia falsa» (Gil, 2011: 306) y, cuando no nos damos

10. ¡Gracias Viti (Ana Vitores) por la referencia en Facebook, aunque no iba dirigida explícitamente a mi! 
cuenta de ello, es el cuerpo el que paga las consecuencias. Quizás por dicho motivo la vivencia aislada en la frontera hace que Frida se configure como una mujer rota:

Tengo muchas contradicciones en mí misma que vienen de este doble papel [...] supongo que de lo que esperaba mi padre de mí, de lo que esperaba mi madre de mí, [...] Soy el típico ejemplo [...] de mujer rota.

De nuevo, es a través de las pinceladas de su homónima Kahlo que podemos ver representada esta situación de ruptura, de dolor, pero también de tenacidad, de fuerza, de resistencia. Así como Kahlo dibujó unas cintas para aguantar su cuerpo quebrado y ayudar a sostener su columna rota, muchas Fridas buscan y encuentran amigos, relaciones, actividades que les ayudan a sostenerse y a seguir activas.

\section{De conclusiones a aprendizajes; de límites a fronteras}

Cuando se llega a la escritura de la parte final de un artículo, suelen esperarse unas conclusiones. Sin embargo, delimitar la producción de saberes es condenarlos a una finitud, crear un límite insuperable. En lugar de conclusiones, y con la finalidad de posicionarnos en las fronteras de la producción del conocimiento colectivo, usaremos este espacio para presentar algunos de los aprendizajes que el encuentro con Frida, el camino hecho en el proceso de análisis y la escritura de este artículo nos han permitido desarrollar.

A nivel metodológico, queremos destacar que hemos vuelto a ser conscientes de la importancia del reconocimiento de la producción del conocimiento a través del diálogo. La relevancia de estimular reflexiones personales a las que da pie el uso de las historias de vida no debe de ser desestimada cuando pensamos en el valor y en el interés social de una investigación: «Te cuento cosas que a mis amigos no les he dicho nunca, porque nunca me puse a pensar en estas cosas».

Nos gustaría subrayar, por otra parte, que las experiencias de Frida nos han sido personalmente útiles para comprender, de una manera más emocional, más encarnada, algo conocido a nivel teórico: las dificultades de habitar los espacios fronterizos. Es más, tal y como Frida declara haberse reconocido en los escritos feministas, yo me encuentro en sus palabras. A pesar de las diferencias de nación, edad, contexto y cultura, muchas de las experiencias, emociones y contradicciones narradas por ella han hecho eco en mí. Esperamos, así, con este artículo, haber sabido trasmitir a más personas las dificultades y los retos que conlleva el vivir en las fronteras, con una especial atención a las fronteras de clase y de género.

Cuando envié a Frida el resumen del proyecto de este artículo, me dijo que no entendía bien si yo interpretaba el vivir en las fronteras como algo negativo o positivo. Ella misma tenia muchas dudas al respecto y no se podía decantar por ninguna de las dos interpretaciones. Insistió, por otra parte, que algo que 
tenía claro era que no quería quedar representada como una víctima de estas fronteras. De acuerdo con ella, y consciente de que victimizar es una forma de inferiorizar la otra, espero haber conseguido no trasmitir esta impresión. Mi intención era mostrar el juego continuo entre las presiones sociales y las decisiones de los sujetos. Si bien no podemos abstraernos de la realidad social que nos envuelve y hemos de ser conscientes de que las posibilidades de elección que tenemos son frecuentemente limitadas, además de que los grupos desfavorecidos son los que tienen menos opciones, no reconocer el ejercicio de decisión de los sujetos, incluso en condiciones de posibilidades extremadamente limitadas, equivale a no respetarles. Mi impresión, escuchando a Frida, es que ella ha puesto en práctica su agencia y ha tomado decisiones sobre su vida, independientemente de que esta haya sido limitada por las condiciones de posibilidad o de que, a posteriori, pueda pensar que ha adoptado la elección equivocada.

Finalmente, y volviendo al tema del artículo (vivir en las fronteras), esperamos que haya quedado patente que no se trata de volver a utilizar categorías cartesianas de bueno y malo para evaluar estas experiencias fronterizas, sino que, por el contrario, debemos entender la complejidad de dichas vivencias. De la misma manera, esperamos haber resaltado la importancia de reconocer la posición epistémica de los sujetos que habitan las fronteras y de trabajar para que los tránsitos, físicos y simbólicos, sean permitidos a todas y todos sin discriminaciones o prejuicios.

\section{Referencias bibliográficas}

AleXANDER-FloYD, Nikol G. (2012). «Disappearing Acts: Reclaiming Intersectionality in the Social Sciences in a Post-Black Feminist Era». Feminist Formations, 24 (1), $1-25$.

ANZALDÚA, Gloria (1987). Borderlands/la frontera. San Francisco: Spinsters / AuntLuteBook Company.

BARKER, Kristin K. (2005). The Fibromyalgia Story: Medical Authority \& Women's Worlds of Pain. Filadelfia, PA: Temple University Press.

Biglia, Barbara (2003). «Transformando dinámicas generizadas: Propuestas de activistas de movimientos sociales mixtos». Athenea Digital, 4, 1-25.

- (2006). "Latin activist women" accounts: Reflection on political research». Feminism \& Psychology, 16 (1), 18-25.

BigliA, Barbara y BONET-MARTí, Jordi (2009). «La construcción de narrativas como método de investigación psicosocial: Prácticas de escritura compartida». Forum Qualitative Sozialforschung / Forum: Qualitative Social Research [en línea], 10 (1), art. 8 [73 párrafos]. <http://nbn-resolving.de/urn:nbn:de:0114-fqs090183>.

- (2014). «Precarity». En: Encyclopedia of Critical Psychology. Springer [versión previa en $<$ http://www.springerreference.com/docs/html/chapterdbid/304881.html $]$.

BigliA, Barbara y VelasCO, Ana (2012). «Reflecting on an academic practice to boost gender awareness in future schoolteachers». Educação, Sociedade \& Culturas, 35, $105-128$.

BUTLER, Judit (2001). El género en disputa: El feminismo y la subversión de la identidad. Barcelona: Paidós, 1999. 
Casado, Elena (1999). "A vueltas con el sujeto del feminismo». Política y Sociedad, 30, 73-91.

Cornejo, Marcela; MendozA, Francisca y Rojas, Rodrigo C. (2008). «La investigación con relatos de vida: Pistas y opciones del diseño metodológico». Psykhe, 17 (1), 29-39.

Crenshaw, Kimberlé (1989). «Demarginalizing the Intersection of Race and Sex: A Black Feminist Critique of Antidiscrimination Doctrine, Feminist Theory and Antiracist Politics». University of Chicago Legal Forum, 67, 139-176.

FACHELli, Sandra y PlANAS, Jordi (2011). «Equidad y movilidad intergeneracional de los titulados universitarios catalanes». Papers, 96 (4), 1283-1307.

GIL, Silvia (2011). Nuevos Feminismos. Sentidos comunes en la dispersión. Madrid: Traficantes de Sueños.

HANSON, Susan (2010). «Gender and Mobility: New Approaches for Informing Sustainability». Gender, Place \& Culture, 17 (1), 5-23.

Heyman, Josiah (2012). "Culture». En: Wood, Andrew G. (ed.). The Borderlands: An Encyclopedia of Culture and Politics on the U.S.-Mexico Divide. Westport: Greenwood Press, 2008.

Junquera, Natalia (2012). "Todos creían que era una espía». El País [en línea], 16 de septiembre. <http://politica.elpais.com/politica/2012/09/14/actualidad/1347652102_676897.html>.

KaHlo, Frida (1932). Self-Portrait Along the Border Line Between Mexico and the United States [en línea]. Nueva York: Colección de María Rodriquez de Reyero. <http://www.fridakahlofans.com/c0110.html>.

- (1944). The Broken Column [en línea]. Ciudad de México: Colección de Dolores Olmedo Patiño. <http://www.fridakahlofans.com/c0480.html>.

La Parra Casado, Daniel (2000). «Desigualdades de género durante la transición a la vida adulta: Un estudio exploratorio». Papers, 61, 131-124.

LindELY, Joanne y MACHIN, Stephen (2012). «The Quest for more and more education: Implication for social mobility». Fiscal Studies, 33 (2), 265-286.

LLORET, Carolina (1997). "Las otras edades o las edades del otro». En: LARrosa, J. y Peres de Lara, N. (ed.). Imágenes del otro. Barcelona: Virus.

Mallimaci, Fortunato y Giménez Béliveau, Verónica (2006). «Historia de vida y métodos biográficos». En: VASILACHIS, Irene (ed.). Estrategias de investigación cualitativa. Barcelona: Gedisa.

NiCOLÁS MARIN, M. Encarna (2007). «La percepción política de las mujeres a través de las historias de vida». En: Vilar Ramírez, Juan Batista; PeŃafiel Ramón, Antonio e Irigoyen LÓPEZ, Antonio (eds.). Historia y sociabilidad: Homenaje a la profesora María del Carmen Melendreras Gimeno. Murcia: Universidad de Murcia.

Pascual de Sans, Àngels (dir.); Miguel Luken, Verónica de; Morén Alegret, Ricard y Solana Solana, Miguel (2002). Migracions a Catalunya: L'estat de la qüestió (1975-2000) [en línia]. Bellaterra: Servei de Publicacions de la Universitat Autònoma de Barcelona. <http://geografia.uab.es/migracions/cas/migracions.pdf>.

PETERSON, Spike V. (2000). "Sexism political identity/nationalism as heterosexism». En: Ranchod-Nilsson, Sita y TÉTreault, Mary Ann (eds). Women State and nationalism. Londres: Routledge.

PlaCER, Fernando (1997). "Identidad, diferencia e indiferencia: El sí mismo como obstáculo». En: LARrosA, J. y PÉrez de LARA, N. Imágenes del otro. Barcelona: Virus, 119-133.

Pujal, Margot (2004). «La identidad (el Self)». En: IBÁÑEZ, Tomás (ed.). Introducción a la psicología social. Barcelona: UOC. 
SASUNKEVICH, Olga (2011). «Place, gender and class on borderlands: Towards a theoretical framework of studying the border between Belarus and Lithuania». Gender Studies \& Research, 9, 52-66.

SEGA, María Teresa (1995). «Passione d'amore e passione politica nella formazione di una "donna nuova" (1876-1915)». En: MAjerotTI, Rita (a cargo de L. Motti). Il Romanzo di una maestra. Roma: Ediesse, Instituto Gramsci.

SeXYsHOCK (2007). «Wonder Bra: Meglio battere che combatiere, 2005». Dibujo reproducido en el artículo "Sexyshock: networks that matter». Feminist Review [en línea], 87, 122-129. <http://www.palgrave-journals.com/fr/journal/v87/n1/ fig_tab/9400365f3.html\#figure-title>.

Subramaniam, Banu (2000). «Snow Brown and the Seven Detergents: A Metanarrative on Science and the Scientific Method». Women's Studies Quartely, 28 (1/2), 296-304.

Zavos, Alexandra; Biglia, Barbara; Clark, Judith y Motzau, Johana (eds.) (2005). "Special Issue on Feminisms and Activisms». Annual Review of Critical Psychology, 4, 1-200. 